\title{
A Prospective Study of Acute Admissions in a Surgical Unit due to Diverticular Disease
}

\author{
S.K.P. John ${ }^{a}$ N.B. Teo ${ }^{b} \quad$ A.L. Forster ${ }^{c}$ \\ a Department of Surgery, Royal Bournemouth Hospital, Bournemouth, ${ }^{b}$ General Surgery, \\ West of Scotland Deanery, Glasgow, and 'Department of Surgery, Ayr Hospital, Ayr, UK
}

\section{Key Words}

Diverticular disease $\cdot$ Recurrent diverticulitis $\cdot C$-reactive protein $\cdot$ CT scan

\begin{abstract}
Introduction: Considerable controversy exists in the surgical literature on the most appropriate treatment modality for patients with recurrent diverticular disease. We aim to assess the clinical outcome of acute surgical admissions with diverticular disease, and in particular patients with recurrent admissions. Methods: 100 consecutive emergency admissions with suspected diverticular disease were prospectively recruited from November 1, 2002 to May 31, 2004. Results: The majority of the patients were female (64\%) and the median age was 74 (45-97) years. The follow-up period was up to 30 months. Four patients with tumour and polyps as definitive diagnosis were excluded from further analysis. Fiftyfour patients had a known history of diverticular disease with a median duration of 4 (range 1-40) years; 44 of them had 1-7 previous emergency admissions (median 2). Acute diverticulitis (42\%) and acute rectal bleeding (23\%) were the commonest presentations. Patients with complicated diverticulitis requiring an emergency operation had a median Creactive protein of $281 \mathrm{mg} / \mathrm{l}$ compared to $58 \mathrm{mg} / \mathrm{l}$ in the con-
\end{abstract}

Presented at 41st World Surgical Congress, Durban, South Africa 2005.

\section{KARGER}

Fax +4161306 1234

E-Mail karger@karger.ch

www.karger.com (c) 2007 S. Karger AG, Basel

0253-4886/07/0243-0186\$23.50/0

Accessible online at:

www.karger.com/dsu servatively treated patients with acute diverticulitis (MannWhitney $U$ test, $Z-3.943, p<0.001$ ). Nine of 14 patients operated had at least two previous admissions with complications of diverticular disease. Emergency operative treatment was associated with prolonged hospital stay ( 21 vs. 5 days; Mann-Whitney U test, $Z-4.367, \mathrm{p}<0.001$ ), increased morbidity and postoperative mortality. Conclusions: Symptomatic diverticular disease is associated with recurrent emergency admissions. The majority of patients who required emergency laparotomy had previous recurrent emergency admissions, which was associated with increased morbidity and prolonged hospital stay.

Copyright $\odot 2007$ S. Karger AG, Basel

\section{Introduction}

Colonic diverticulosis is a common condition, especially in the developed world. About a third of the population is affected by the 6th decade and half by the 9th decade. No clear-cut guideline or management strategy addresses the whole spectrum of diverticular disease.

There is no uniform definition of diverticular disease in the current literature $[1,2]$. A consensus development conference in 1998 defined diverticular disease as a condition seen mostly in the sigmoid colon, characterised by mucosal herniation through the colonic wall, generally accompanied by elastosis of the taenia coli and mucosal folding $[3,4]$. The asymptomatic condition is known as

Mr. Solomon K.P. John

Research Registrar

Royal Bournemouth Hospital

Bournemouth BH7 7DW (UK)

Tel. +44 779151 9726, Fax +44 120270 4613, E-Mail john3solomon@hotmail.com 
diverticulosis. Symptomatic diverticular disease may be complicated or uncomplicated. The term 'diverticulitis' is used to indicate superadded inflammation and or infection involving the bowel wall. Perforation, fistula, obstruction and bleeding are the other complications described [3].

The prognosis of patients admitted to hospital with diverticular disease is uncertain owing to the poor quality data mostly from retrospective series and the limited number of prospective studies [4-7]. A recent trend in the surgical literature, mainly based on retrospective studies, has been towards a non-surgical approach after a second attack of diverticulitis $[5,6]$. This conservative approach is contrary to views expressed in the practice parameters and there is suggestion that this ongoing debate needs more evidence from well-designed large prospective series [10].

We aim to assess the clinical outcome of emergency admissions with diverticular disease and whether emergency surgical intervention in symptomatic diverticular disease was more commonly associated with previous recurrent admissions. The secondary outcomes analysed included: previous recurrent admission rate with symptomatic diverticular disease; the role of $\mathrm{C}$-reactive protein (CRP) and white cell count (WBC) as predictors of severity in the emergency operated group with diverticulitis; the post-operative morbidity, mortality and hospital stay, and finally Hartmann's reversal rate within the period of follow-up.

\section{Methods}

Patients with symptomatic diverticular disease admitted as emergency were recruited prospectively between November 1, 2002, and May 31, 2004, in a Surgical Unit in the West of Scotland. The patients were referred by general practitioners or presented acutely to the Accident and Emergency Department.

The inclusion criteria were: (1) emergency presentation with diverticulitis confirmed by imaging (CT scan) and endoscopy; (2) rectal bleeding where other causes had been ruled out by flexible sigmoidoscopy and barium enema or colonoscopy; (3) other presentations including pneumaturia, faecouria and dysuria for colovesical fistula (proven by CT with contrast and or gastrograffin enema), and (4) signs and symptoms of large bowel obstruction where other causes had been ruled out by endoscopy and or imaging (CT scan) during and after admission.

The exclusion criteria were: (1) patients diagnosed with colorectal cancer during the admission/study period or those with a known history of colorectal cancer, and (2) patients presenting with rectal bleeding as the only presentation where other primary causes were found on flexible sigmoidoscopy or barium enema or colonoscopy.

Acute Admissions due to Diverticular Disease
The data collected were recorded using Microsoft Access 2002. The results were analysed with Prism Graph Pad version 4 statistical software and SPSS version 12 (Chicago, Ill., USA).

\section{Results}

One hundred patients were recruited over a period of 20 months, of which 64 were female. The overall median age was 74 (range 45-97) years.

\section{Clinical Presentation (Index Admission)}

Forty-two patients (42\%) presented with acute diverticulitis and 23 patients $(23 \%)$ with rectal bleeding during the index admission (fig. 1). Seventeen patients (17\%) had clinical signs of acute diverticulitis and a positive history of passing a trivial amount of blood rectally.

Later 4 patients with colorectal neoplastic lesions and coexisting diverticular disease were excluded from further analysis. Investigations, namely CT scans, flexible sigmoidoscopy, colonoscopy and barium enema in various combinations, were carried out in this cohort of patients.

\section{Past History of Diverticular Disease}

Fifty-four patients had a previous history of diverticular disease confirmed by both barium enema and flexible sigmoidoscopy $(n=49)$ or barium enema only $(n=5$; table 1). The duration of symptomatic diverticular disease in these patients varied from 1 to 40 (median 4) years. Forty-four of these 54 patients had up to 7 (median 2) previous emergency admissions with symptomatic diverticular disease.

\section{Treatment (Index Admission)}

The majority of patients were treated conservatively with intravenous antibiotics and/or blood transfusion $(n=80)$. Fourteen patients ended up having emergency laparotomy and 2 patients needed CT-guided drainage of a diverticular abscess (table 2). The predominant indication for an emergency surgery was purulent or faecal peritonitis in the operated group, Hinchey 3 and 4 [7], and Hartmann's resection was the commonest surgery performed in the study (tables 2, 3).

\section{Recurrent Disease in the Operated Group}

Nine of 14 emergency laparotomy patients had previous recurrent acute admissions with diverticular disease (7 with acute diverticulitis, and 2 with rectal bleeding). The other 5 patients, 4 of whom were under 50 years of age, did not have previous admission with the disease.

Dig Surg 2007;24:186-190 
Table 1. Patients with previous presentation of diverticular disease

\begin{tabular}{lr}
\hline Diverticulitis & 27 \\
Bleeding & 16 \\
Complicated diverticulitis & 5 \\
Not recorded & 6
\end{tabular}

Table 2. Indications for emergency laparotomy $(\mathrm{n}=14)$

Purulent/faecal peritonitis

(Hinchey 3 and 4)

Abscess (Hinchey 2)

Fistula (colovesical 2, colovaginal 1)

Rectal bleeding

Table 3. Types of emergency laparotomy $(\mathrm{n}=14)$

\begin{tabular}{ll} 
Hartmann's procedure & 6 \\
Anterior resection/sigmoid colectomy & 6 \\
Subtotal colectomy & 1 \\
Transverse loop colostomy & 1 \\
\hline
\end{tabular}

\section{Morbidity in Young Patients}

Six patients were below 50 years and all were male. Four of them required surgery either at the index admission (2 patients) or early elective surgery and excision of colovesical fistula within 1 month after hospital discharge in 2 patients.

\section{Inflammatory Markers (within $4 \mathrm{~h}$ of Admission)}

Patients with an abscess and/or peritonitis had significantly raised median CRP compared to the conservatively treated patients with acute diverticulitis: 281 (20396) $\mathrm{mg} / \mathrm{l}, \mathrm{n}=11$, versus 58 (5-332) $\mathrm{mg} / \mathrm{l}$ (Mann-Whitney $\mathrm{U}$ test, $\mathrm{Z}-3.943, \mathrm{p}<0.001)$. No significant difference was noted in admission WBC count $(\mathrm{n}=96)$ in the operated (median $9.9 \cdot 10^{9} / \mathrm{mm}^{3}$ ) and conservatively treated group (median $10.75 \cdot 10^{9} / \mathrm{mm}^{3}$; fig. 2).

\section{Morbidity and Mortality}

Increased morbidity was noted in the emergency operated group including: intra-operative splenic tear requiring a splenectomy in 1 patient; chest infection $(n=7)$;

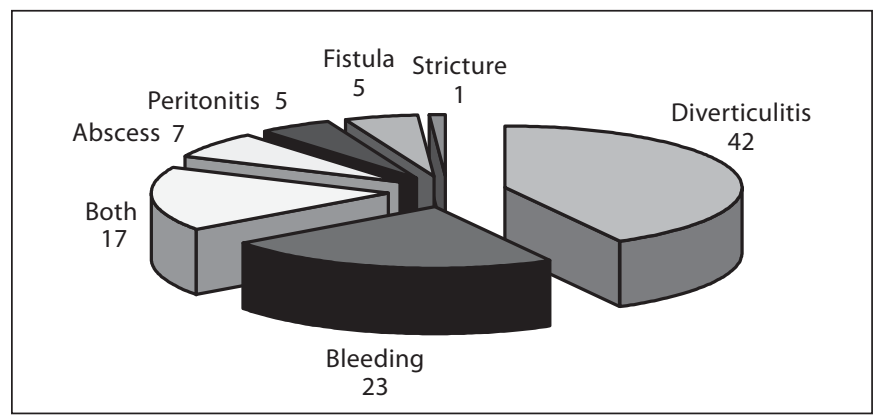

Fig. 1. Clinical presentation at the index admission $(n=100)$.

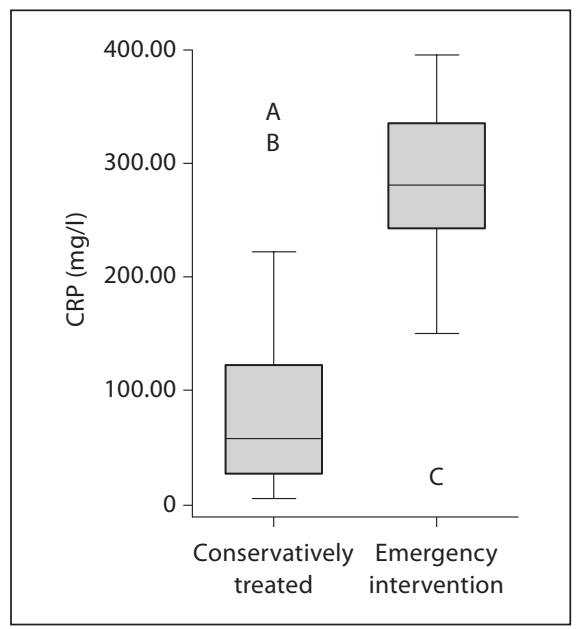

Fig. 2. C-reactive protein (CRP) values within $4 \mathrm{~h}$ of admission in the conservative treatment and operated group of patients with diverticulitis. Outliers: $\mathrm{A}=332 \mathrm{mg} / \mathrm{l} ; \mathrm{B}=307 \mathrm{mg} / \mathrm{l} ; \mathrm{C}=20 \mathrm{mg} / \mathrm{l}$.

electrolyte disturbances $(n=6)$; wound infection $(n=2)$, and cerebrovascular event $(n=1)$. This was in comparison to no major morbidity recorded for the conservatively treated group. Overall 7 patients died during the follow-up period including: 2 postoperatively; 1 on the 30 th day in hospital, and 4 due to cardiovascular causes and old age in the community.

\section{Follow-Up}

The overall follow-up period was 30 (median 22, interquartile range (IQR) 15-26) months. Follow-up data were available for 72 patients, including those who underwent delayed investigations. As for those with a previous history of diverticular disease $(\mathrm{n}=54), 9$ had no follow-up data. Seven and 3 patients in this group with known diverticular disease were readmitted with diverticulitis and per-rectal bleeding, respectively, during the follow-up pe- 
riod. None of the patients with a first attack of diverticular disease was readmitted during this follow-up period. In the operated group only 1 patient was readmitted with left lower quadrant pain. At the end of the follow-up period, only 2 patients had their stoma reversed: 1 from Hartmann's procedure, and the other from a covering loop ileostomy after an anterior resection.

\section{Hospital Stay}

The median hospital stay for the 96 patients was 6 (IQR 4-13) days. The median hospital stay for those with recurrent admissions in the past was 10 (IQR 4-28) days. Those requiring surgical intervention at the index admission had a median hospital stay of 21 (IQR 12-33) days compared to 5 (IQR 3-10) days among those who were treated conservatively (Mann-Whitney $\mathrm{U}$ test, $\mathrm{Z}-4.367$, $\mathrm{p}<0.001)$.

\section{Discussion}

Little is known of the natural history of diverticular disease. Prospective studies to date indicate that $80-85 \%$ of the cases are asymptomatic $[8,9]$. The other $15-20 \%$ present with painful diverticular disease, of which $25 \%$ are complicated by inflammation and bleeding [1]. The prolonged duration of this condition is well recognised $[9,10]$ and this is well reflected in our study with a median duration of 4 (range 1-40) years since the first presentation. Our follow-up data indicate higher recurrent symptomatic admissions for those with a past history of proven diverticular disease.

Our current practice is to adopt a conservative approach in the majority of emergency admissions. There is a general consensus that conservative treatment is indicated in new cases of uncomplicated diverticular disease as shown by previous studies $[3,11] .50-70 \%$ of patients treated for the first episode will recover and remain asymptomatic [3]. The other $20 \%$ may have recurrent attacks, of which $60 \%$ develop complications [12]. Somasekar et al. [13] looked at complicated diverticular disease retrospectively and found that only $2.7 \%$ had previous attacks of diverticulitis and $26 \%$ had a history of diverticular disease. However, $44 \%$ patients in our series had previous recurrent acute admissions (median 2) secondary to diverticular disease (range 1-7). Although retrospective data of previous episodes were accurately coded based on investigations at previous admissions, inherent difficulties with such data analysis is always recognised.

Acute Admissions due to Diverticular Disease
Our findings raised the possibility that a proportion of these patients would benefit from prophylactic colonic resection as 9 of 14 patients operated had previous recurrent acute admissions for diverticulitis [3]. This policy is not often followed in our hospital and we incline towards conservative management in the presence of patients' medical co-morbidities. The benefit of an elective resection for recurrent symptoms should be weighed against the risks of an emergency surgery in old and fragile patients as well as those with concurrent disease $[2,5,14]$. In this study, emergency operations were associated with significant morbidity, mortality and prolonged hospital stay implying the consequences of an emergency surgery in a high-risk population of patients. Our finding strengthens the concept laid down in the practice parameters, though we acknowledge larger prospective studies could eliminate much of the current confusion in surgical practice in symptomatic diverticular disease.

Four of six patients below 50 years of age in this study had surgical intervention after one attack of diverticulitis. Previous studies, including a series by Schauer et al. [14], reported $26 \%$ of 238 patients to be below 40 years, and $72 \%$ of them required an urgent surgical intervention [15]. Although some surgeons recommend an elective resection in young patients after one well-documented episode of uncomplicated diverticulitis, two recent studies and a review paper failed to substantiate a more aggressive nature of diverticulitis in young patients $[6,16,17]$. This could possibly be explained by the lack of long-term prospective studies in the younger population to evaluate the natural history of diverticular disease in this age group.

Data on prognostic indicators that might predict the recurrence or severity of diverticular disease are still lacking to date. In our series, a significantly raised CRP (median of $281 \mathrm{mg} / \mathrm{l}$ ) on admission was noted among those patients with abscess formation, peritonitis, and this might have value in stratifying a subgroup of patients who require an early CT scan along with timely appropriate intervention. Colecchia et al. [18] suggested that the colonic motility index (pressure amplitude exceeding 120 $\mathrm{mm} \mathrm{Hg}$ ), with a history of left lower quadrant pain, short segment of bowel involvement, and younger age $(<50$ years) may be useful in identifying a patient population at risk of complications.

Almost half of the emergency laparotomies ended up with Hartmann's procedure (6/14) and 1 patient had a loop colostomy. The poor general condition of those with Hinchey 3 and 4 was the main indication for Hartmann's procedure. In a British National Audit study, Tudor et al. [19] recommended early surgery and Hartmann's proce-

Dig Surg 2007;24:186-190 
dure if percutaneous drainage failed in the elderly as sepsis is poorly tolerated. The recent trend is towards primary resection and anastomosis, except in the presence of diffuse pelvic peritonitis [20] and obstructing complicated diverticular disease [21]. A higher complication rate and prolonged hospital stay was also noted in the Hartmann's group compared to the primary anastomosis group in a recent French study [22].

Co-morbidity in the elderly population constitutes a hindrance to stoma closure. We reported only 1 case of reversal out of 6 Hartmann's procedures after a follow-up of 30 months. Closure of Hartmann's colostomy is a safe procedure but has a significant morbidity in a third of the cases [23]. An early ( $<4$ months) reversal of Hartmann's is preferred in most studies, when the rectal stump is most accessible [23]. The literature suggests that nearly a third of patients never have their stoma reversed [20,23, $24]$. The low rate of stoma closure in our series reflects the degree of co-morbidity in these patients.

\section{Conclusions}

Conservative management for acute admissions with diverticular disease was associated with recurrent admissions in the acute setting. Nine of 14 patients operated on an emergency basis had had recurrent acute admissions in the past. Emergency surgery was associated with increased morbidity, post-operative mortality, prolonged hospital stay and a low rate of colostomy reversal.

The role of elective colectomy for diverticular disease needs to be revisited through larger and possibly multicentre prospective trials.

\section{Acknowledgement}

The authors would like to thank Mr. R.L. Mehta (Statistician), Research and Development Support Unit (RDSU), Southampton General Hospital, for his assistance.

\section{References}

1 Farrell RJ, Farrell JJ, Morin MM: Diverticular disease in the elderly. Gastroenterol Clin North Am 2001;30:475-496.

$\checkmark 2$ Ferzoco LB, Raptopoulos V, Silen W: Acute diverticulitis. N Engl J Med 1998;338:15211526.

-3 Kohler L, Sauerland S, Neugebauer E: Diagnosis and treatment of diverticular disease: results of consensus development conference. The Scientific Committee of the European Association for Endoscopic Surgery. Surg Endosc 1999;13:430-436.

4 Whiteway J, Morson BC: Elastosis in diverticular disease of the sigmoid colon. Gut 1985;26:258-266.

5 Chapman JRM, Dozois EJM, Wolff BGM, Gullerud REB, Larson DRM: Diverticulitis: a progressive disease? Do multiple recurrences predict less favorable outcomes? Ann Surg 2006;243:876-883.

-6 Janes S, Meagher A, Frizelle FA: Elective surgery after acute diverticulitis. Br J Surg 2005; 92:133-142.

7 Hinchey EJ, Schaal PH, Richards MB: Treatment of perforated diverticular disease of the colon. Adv Surg 1978;12:85-109.

-8 Haglund U, Hellberg R, Johnsen C, Hulten L: Complicated diverticular disease of the sigmoid colon. An analysis of short and long term outcome in 392 patients. Ann Chir Gynaecol 1979;68:41-46.

-9 Parks TG: Natural history of diverticular disease of the colon. Clin Gastroentero $1975 ; 4: 53-79$
10 Wong WD, Wexner SD, Lowry A, Vernava A 3rd, Burnstein M, Denstman F, Fazio V, Kerner B, Moore R, Oliver G, Peters W, Ross T, Senatore P, Simmang C: Practice parameters for the treatment of sigmoid diverticulitis - supporting documentation. The Standards Task Force. The American Society of Colon and Rectal Surgeons. Dis Colon Rectum 2000;43:290-297.

11 Stollman NH, Raskin JB: Practice guidelines, diagnosis and management of diverticular disease of the colon in adults. Ad Hoc Practice Parameters Committee of the American College of Gastroenterology. Am J Gastroenterol 1999;94:3110-3120.

12 Farmakis N, Tudor RG, Keighley MR: The five year natural history of complicated diverticular disease. Br J Surg 1994;81:733-735.

13 Somasekar K, Foster ME, Haray PN: The natural history diverticular disease: is there a role for elective colectomy. J R Coll Surg Edinb 2002;47:481-484.

14 Schauer PR, Ramos R, Ghiatas A, Sirinek KR: Virulent diverticular disease of the colon in young obese men. Am J Surg 1992;164: 443-448.

15 Konvolinka CW: Acute diverticulitis under age forty. Am J Surg 1994;167:562-565.

-16 Spivak H, Weinrauch S, Harvey JC, Surick B, Ferstenberg H, Friedman I: Acute colonic diverticulitis in the young. Dis Colon Rectum 1997;40:570-574.

17 Vignati PV, Welch JP, Cohen JL: Long term management of diverticulitis in young patients. Dis Colon Rectum 1995;38:627-629.
18 Colecchia A, Sandri L, Capodicasa S, Vestito A, Mazzella G, Staniscia T, Roda E, Festi D: Diverticular disease of the colon: new perspectives in symptom development and treatment. World J Gastroenterol 2003;9: 1385-1389.

19 Tudor RG, Farmakis N, Keighley MR: National audit of complicated diverticular disease: analysis of index cases. Br J Surg 1994; 81:730-732.

20 Belmonte C, Klas JV, Perez JJ, Wong WD, Rothenberger DA, Goldberg SM, Madoff RD: The Hartmann procedure. First choice or last resort in diverticular disease. Arch Surg 1996;131:612-615.

21 Gooszen AW, Tollenaar RA, Geelkerken RH, Smeets HJ, Bemelman WA, Van Schaardenburgh P, Gooszen HG: Prospective study of primary anastomoses following sigmoid resection for suspected acute complicated diverticular disease. Br J Surg 2001;88:693697.

22 Regenet N, Tuech JJ, Pessaux P, Ziani M, Rouge C, Hennekinne S, Arnaud JP: Intraoperative colonic lavage with primary anastomosis vs. Hartmann's procedure for perforated diverticular disease of colon: a consecutive study. Hepatogastroenterology 2002;49:664-667.

23 Roe AM, Prabhu S, Ali A, Brown C, Brodribb AJ: Reversal of Hartmann's procedure: timing and operative technique. Br J Surg 1991; 78:1167-1170.

24 Moshe S: Diverticulitis - current treatment options. Infect Dis 2000;2:332-341. 